\title{
STUDY ON DYNAMIC PROPERTIES OF STRUCTURAL COMPOSITE SYSTEMS EQUIPPING SAFETY GUARDRAILS
}

\author{
JIGA, G[heorghe] - G[abriel]; DINU, G[abriela]; VLASCEANU, D[aniel] \& OPRAN, C[onstantin]
}

\begin{abstract}
In this paper are presented the results of a research activity on the impact behavior of safety barriers destined to road networks. Thus, numerical and experimental analysis methods will be relieved as well as the composite materials integrity destined to the design and manufacturing of these barriers, highlighting the structural performances destined for impact loadings. Also, the functional and constructive variants of these systems will be analyzed under an innovative version in order to offer a predictable answer for the direct impact, to insure the human - machine - environment system protection on national roads.

Keywords: Safety guardrail, impact, composite system, structural analysis, traffic safety, FEM modeling.
\end{abstract}

\section{INTRODUCTION}

Romania is developing and modernizing its road network to face the new transport model resulted in the development of its economy.

As part of this process, Romania leads an active policy of greater accessibility to commercial and economic connections with its neighbors and other European Union countries. It is therefore important that the road network is effectively responding to an efficient traffic demand.

The establishment of binding rules for the design, construction and roads modernization combined with buildings location and facilities in their area, have to ensure, in terms of high-tech and economic efficiency, a joining of judicious system of public roads and exploitation, to preserve and to enhance the capitalization of existing road network, upgrading and saving the rational use of land in order to increase efficiency and road safety.

Any safety railing manufacturer must hold a test report, known as crash-test. It is done in only two places in all Europe - in Munich and Lyon - and costs around 200,000 Euros. As such, domestic manufacturer has not yet allowed achieving these tests and consequently equipment located on roads in our country are several times done empirically. Over half of these roads have protective barriers, walkways and posts for marking which do not correspond to European standards of traffic safety. In accordance with the rules imposed by the European Union and adopted a long time ago by our country, railing manufacturers must have a number of certificates and test reports for the product. In this context our paper intends to present the research activity developed in ICECON S.A. in order to improve the impact attenuation of safety barriers using new damping elements.

\section{PERFORMANCE REQUIREMENTS FOR PROTECTIVE BARRIERS EQUIPPING THE PUBLIC ROADS}

The protective barriers primary aims are to stop and to return the vehicles on the carriageway, ensuring a leading of pedestrians and other road users.

Also, safety guardrails are placed on hazardous road sections in terms of traffic safety, to protect vehicles against exits from the road platform and to guide them optically.

The protective barrier is mounted on the verge mower or on the road median strip. Function of different parameters the safety barriers are divided in three different classes as follows:

a) According to the duration of use:

- Permanent safety barrier;

- Temporary safety barrier.

b) According to impact behavior:

- Deformable safety barrier;

- Stiff safety barrier.

c) According to how the shock is taking over:

- Simply safety barrier;

- Double safety barrier.

Stiff guardrails shall be made of concrete or stone masonry and could be divided into three different types: slight, hard and very hard. These barriers are provided for optical guidance as well as for the prevention of vehicles to leave the road platform in certain limits of velocity, mass and toe tap, not providing or bringing vehicles on the roadway.

Opposed to those of the first category, deformable guardrails are made of metal elements and could be divided into semi-hard, hard and very hard types.

These fences allow the slippage or roll over of the wheel rim along them getting back on the carriageway. This type of barrier is used generally on European highways.

Guardrails behavior and their resistance to shock produced by possible impact of some vehicles, depend on the incidence angle of impact. If this angle is greater than $15^{\circ}$, the barrier can not provide usually the guidance or the vehicles recovery.

The choice of composite structure involves as well material selection, as optimization layer configuration and design of structural elements. 
The achievement of a certain configuration requirements is based on one or more design parameters among which could be mentioned:

- Stiffness;

- Strength;

- Dynamic stability;

- Environmental stability;

- Tolerability for different types of damage.

In addition to the initial requirements imposed for the composite structure, the quality, durability and safety in use conditions must be accomplished.

The optimal laminates with respect to their strength are those which have a high value of $\varphi_{\mathrm{L}}$. This ratio measures the laminate efficiency and indicates the use level of fibers with high strength. So,

$$
\varphi_{\mathrm{L}}=\frac{\overline{\mathrm{F}}_{\mathrm{xt}}^{(1)}}{\overline{\mathrm{F}}_{\mathrm{Xt}}^{\mathrm{u}}}=\frac{\overline{\mathrm{F}}_{\mathrm{FPF}}}{\overline{\mathrm{F}}_{\mathrm{ULF}}},
$$

where:

$\overline{\mathrm{F}}_{\text {FPF }}$ represents the necessary load for the breaking of the first fiber;

$\overline{\mathrm{F}}_{\text {ULF }}$ is the load necessary for the failure of the whole laminate.

This ratio depends also on the laminated stacking sequence.

\section{MODELING OF MECHANICAL BEHAVIOR OF DIFFERENT MATERIALS USED IN THE GUARDRAILS MANUFACTURING}

In order to model the mechanical behavior, different materials were analyzed, starting from the traditional ones (steel and its alloys) and ending with laminated fiber reinforced composite structures or sandwich structures [1], [2].

In this context, a steel strip with variable thickness between 3 and $5 \mathrm{~mm}$, as one can observe in Fig.1. Two of the opposite sides, with dimensions $300 \times 150 \mathrm{~mm}^{2}$, have been fixed, the tape being loaded in its center by the weight of the mass which falls from the height $h$. For the modeling of the impacted force, using FEM, in order to avoid high stress values during post-processing due to stress concentrators the concentrated force was equated to a uniformly distributed load over a circular area, with dimensions equivalent to those of the impactor.

In order to mesh the strip the SHELL93 plate element was selected. This element has six degrees of freedom on each node: three translations axes $x, y$ and $z$ and three rotations to the same axis. SHELL93 element has plasticity, displacement and high deformation values, element geometry, location of nodes and coordinate system of this type of item are shown in Fig.2.

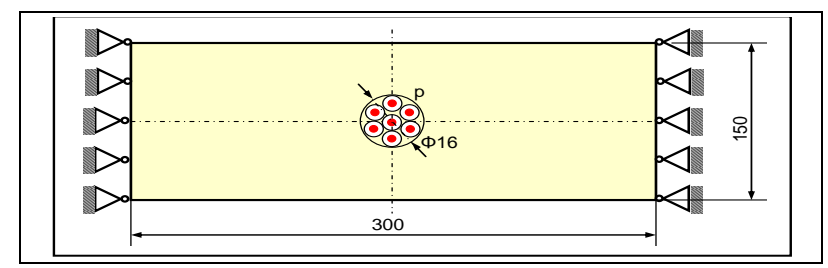

Fig. 1. The strip modeling

This element is characterized by eight nodes, four thicknesses and material orthotropy properties. Nodes located in the middle of the thickness of the element may or may not be declared. The orthotropic material directions correspond to the directions of the coordinate system attached to the element.

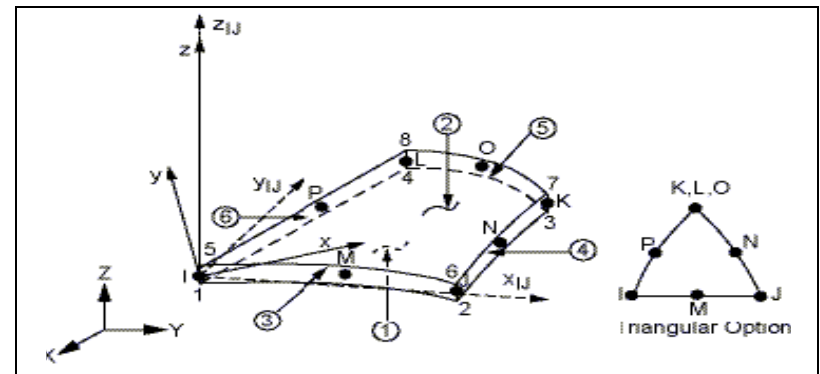

Fig.2 Description of SHELL 93 plate element

$\mathrm{X}$ and $\mathrm{Y}$ axes are in the plane of the plate and the $\mathrm{Z}$ axis perpendicular to its plane. $\mathrm{X}$-axis can be rotated by the angle $\theta[0]$ to $\mathrm{Y}$. The element may have variable thickness. This thickness variation is assumed to have a smooth surface element being introduced as an input data in the element bends

Concerning the application of the load it could be introduced as well concentrated forces applied to nodes as pressures on the faces of one or more elements.

Apart the classic case (with sheet steel), other materials such as laminated composites made of glass fiber reinforced composite sandwich or cored with foam and steel strips were also analyzed.

For each case the following data were determined: - maximum $\mathrm{w}_{\max }$ deflection;

- maximum equivalent stress (Von Mises);

- energy stored in the structure during the application.

Finite element analysis was performed for panels made of three different types of materials (steel, laminated glass fiber reinforced epoxy matrix composite, laminated sandwich foam core and steel strips). For all panels was monitored their behavior to different types of loading for a required thickness.

\section{OBTAINED RESULTS}

Fig.3 shows the finite element mesh for the panel analyzed. This was achieved using triangular elements, resulting finally a structure with 8788 a multi-elements and 17,757 nodes.

In Fig.4 is shown the loading and the bearing system.

Concerning the boundary conditions the authors tried to respect the real conditions required by a safety 
guardrail. In the layered glass fibers reinforced composite in order to check what type of configuration is optimal to take over impact there were analyzed four different configurations, $[0 / \pm 45 / 0]_{\mathrm{S}},[-45 / 0 / 45 / 0]_{\mathrm{S}}$, $[ \pm 45 / 02]_{S},[-45 / 02 / 45]_{S}$ [3], [4].

The finite element analysis performed on the following types of panels is shown in Table 1.

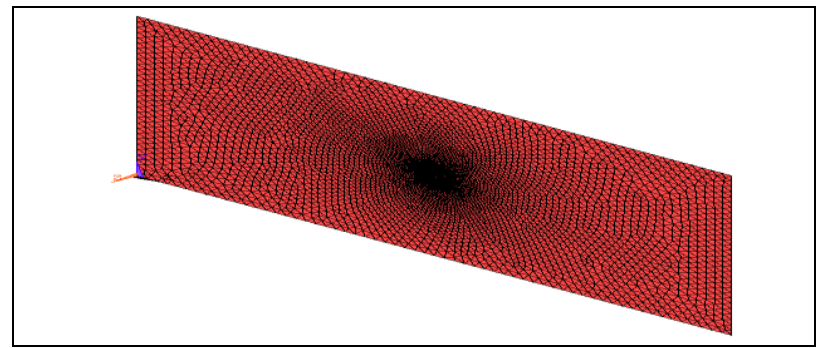

Fig.3. Panel meshing

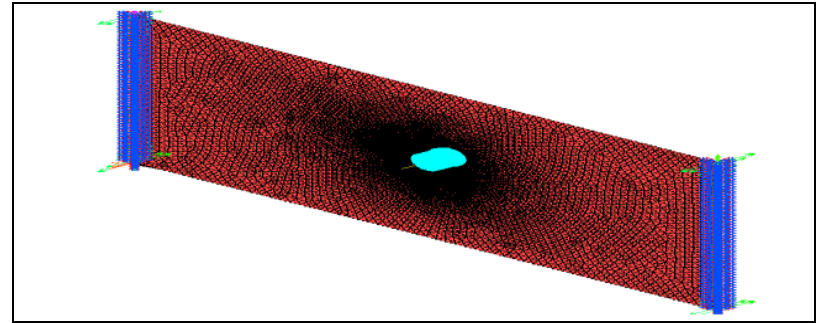

Fig.4. The loading and bearing system

\begin{tabular}{|c|c|c|c|c|}
\hline Material & $\begin{array}{c}\text { Panel } \\
\text { thickness } \\
{[\mathrm{mm}]} \\
\end{array}$ & $\begin{array}{c}\mathrm{F} \\
{[\mathrm{N}]}\end{array}$ & $\begin{array}{c}\text { Equival. } \\
\text { pressure } \\
\text { [MPa] } \\
\end{array}$ & $\begin{array}{l}\text { Elastic } \\
\text { constants }\end{array}$ \\
\hline \multirow{12}{*}{ Steel } & \multirow{4}{*}{3} & 30 & 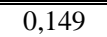 & \multirow{12}{*}{$\begin{array}{c}\mathrm{E}=21 \cdot 10^{4} \mathrm{MPa} \\
\nu=0,3 \\
\mathrm{G}=8 \cdot 10^{4} \mathrm{MPa}\end{array}$} \\
\hline & & 40 & 0,198 & \\
\hline & & 50 & 0,248 & \\
\hline & & 60 & 0,298 & \\
\hline & \multirow{4}{*}{4} & 30 & 0,149 & \\
\hline & & 40 & 0,198 & \\
\hline & & 50 & 0,248 & \\
\hline & & 60 & 0,298 & \\
\hline & \multirow{4}{*}{5} & 30 & 0,149 & \\
\hline & & 40 & 0,198 & \\
\hline & & 50 & 0,248 & \\
\hline & & 60 & 0,298 & \\
\hline \multirow{12}{*}{$\begin{array}{l}\text { Fiber glass } \\
\text { reinforced } \\
\text { composite }\end{array}$} & \multirow{4}{*}{3} & 30 & 0,149 & \multirow{12}{*}{$\begin{aligned} \mathrm{E}_{1} & =146,9 \mathrm{GPa} \\
\mathrm{E}_{2} & =10,89 \mathrm{GPa} \\
\mathrm{E}_{3} & =10,89 \mathrm{GPa} \\
\mathrm{G}_{12} & =10,89 \mathrm{GPa} \\
\mathrm{G}_{23} & =6,4 \mathrm{GPa} \\
\mathrm{G}_{13} & =10,89 \mathrm{GPa} \\
v_{12} & =v_{13}=0,38 \\
v_{23} & =0,776\end{aligned}$} \\
\hline & & 40 & 0,198 & \\
\hline & & 50 & 0,248 & \\
\hline & & 60 & 0,298 & \\
\hline & \multirow{4}{*}{4} & 30 & 0,149 & \\
\hline & & 40 & 0,198 & \\
\hline & & 50 & 0,248 & \\
\hline & & 60 & 0,298 & \\
\hline & \multirow{4}{*}{5} & 30 & 0,149 & \\
\hline & & 40 & 0,198 & \\
\hline & & 50 & 0,248 & \\
\hline & & 60 & 0,298 & \\
\hline \multirow{12}{*}{$\begin{array}{c}\text { Sandwich } \\
\text { composite } \\
\text { structure } \\
\text { (steel strips } \\
\text { + poly- } \\
\text { urethane } \\
\text { foam) }\end{array}$} & \multirow{4}{*}{3} & 30 & 0,149 & \multirow{12}{*}{$\begin{array}{c}\text { Polyurethane } \\
\quad \text { foam } \\
\mathrm{E}=25 \mathrm{MPa} \\
v=0,25\end{array}$} \\
\hline & & 40 & 0,198 & \\
\hline & & 50 & 0,248 & \\
\hline & & 60 & 0,298 & \\
\hline & \multirow{4}{*}{4} & 30 & 0,149 & \\
\hline & & 40 & 0,198 & \\
\hline & & 50 & 0,248 & \\
\hline & & 60 & 0,298 & \\
\hline & \multirow{4}{*}{5} & 30 & 0,149 & \\
\hline & & 40 & 0,198 & \\
\hline & & 50 & 0,248 & \\
\hline & & 60 & 0,298 & \\
\hline
\end{tabular}

Table.1. Finite element analysis performed on the following types of panels
In Fig. 5 to 7 are presented the results obtained from the finite element analysis of panel made of sheet steel with thickness of $3 \mathrm{~mm}$ and with a load of $30 \mathrm{~N}$. These results concerns both the deformed structure, the displacement variation expressed in $[\mathrm{mm}]$ as the equivalent Von Mises stress distribution calculated in the center of each element expressed in [MPa].

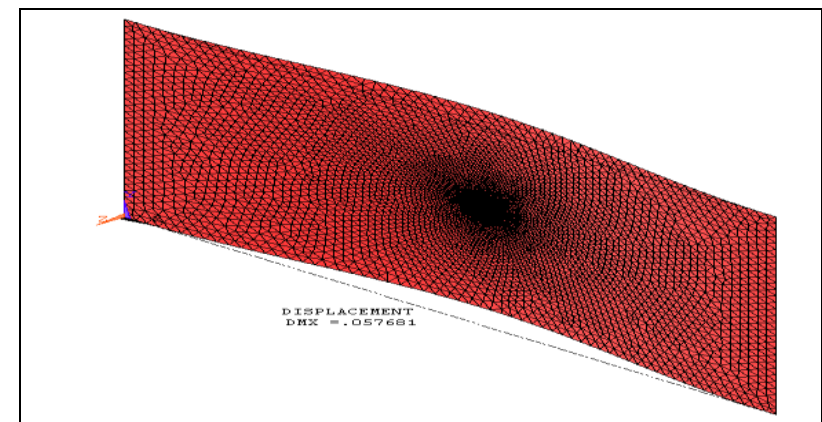

Fig.5. Deformed structure of a $3 \mathrm{~mm}$ steel strip with $\mathrm{F}=30 \mathrm{~N}$

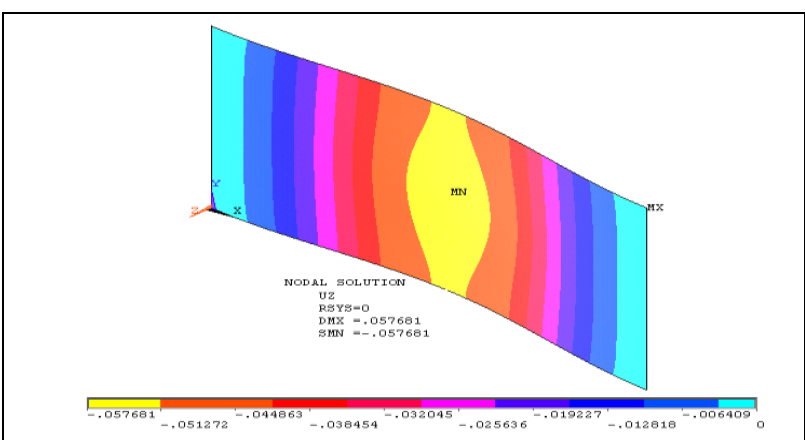

Fig.6 The displacement variation of the $3 \mathrm{~mm}$ steel strip with an applied force of $30 \mathrm{~N}$

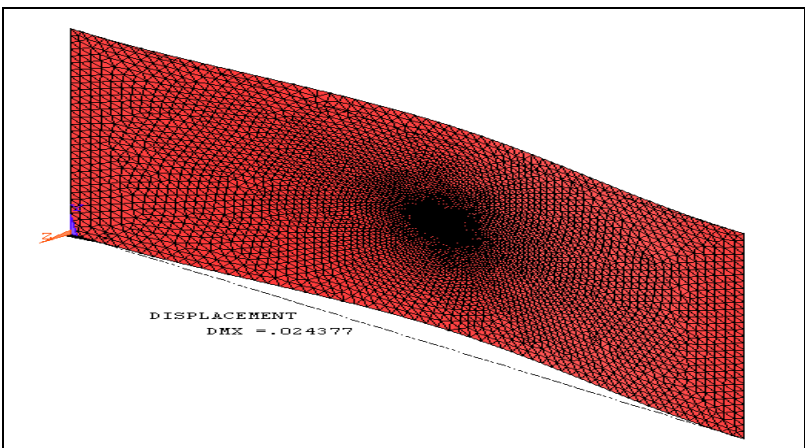

Fig.7. Von Mises equivalent stress for the $3 \mathrm{~mm}$ steel strip panel, with a force $\mathrm{F}=30 \mathrm{~N}$

In fig. 8 is plotted the variation of the strain energy as a function of the force applied for three different thicknesses of the strip [5], [6]. In fig. 9 is presented the maximum equivalent stress variation $\left(\sigma_{\max }\right)$ depending on the thickness of steel panel, for four levels of loading. 


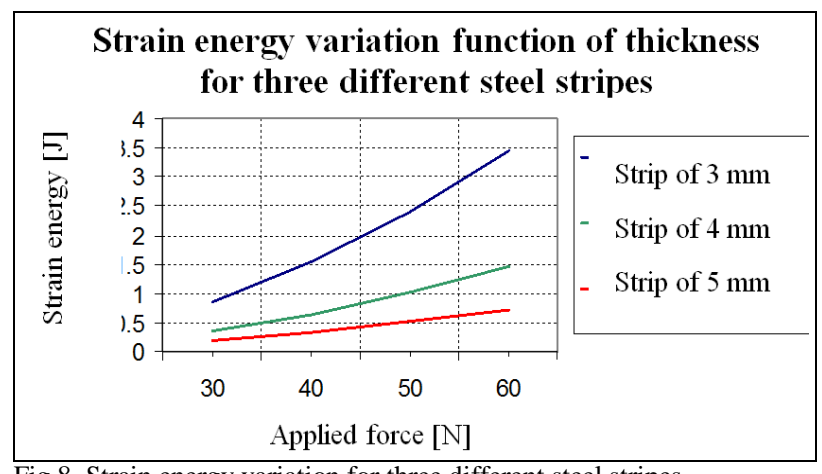

Fig.8. Strain energy variation for three different steel stripes

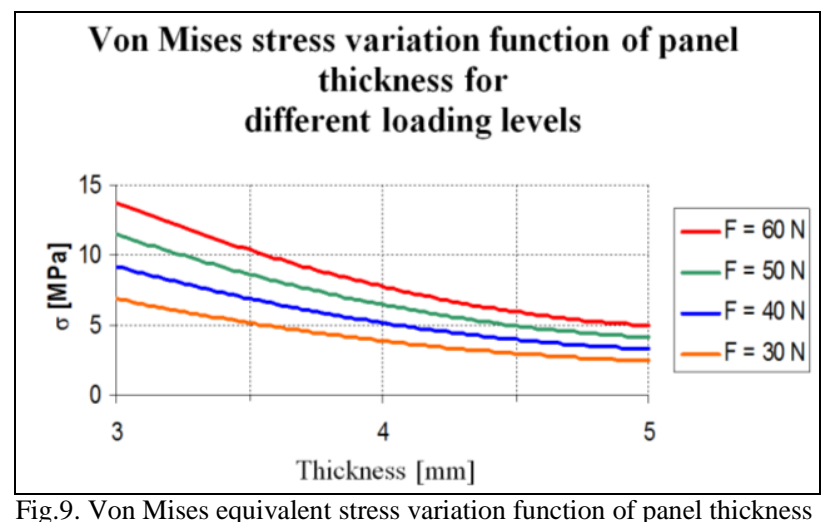

\section{CONCLUSIONS}

In order to maintain and improve the road safety, the design of a road requires on some sectors and in some places the installation of devices destined to prevent vehicles and pedestrians from entering in dangerous areas.

Protective guardrails studied in this paper are classified for different performance levels, designed to stop vehicles, to return them on the carriageway and to provide the guiding of pedestrians and of other road users.

In accordance with the existing standards there are set different levels of performance for three main criteria, including:

- The level of protection (T1, T2 etc.);

- The level of severity of shock (A or B);

- Deformation expressed by the working width $\left(\mathrm{W}_{1}\right.$, $\mathrm{W}_{2}$ ).

In accordance with current standards could be used several types of fences; they may differ from each other by their functions on one hand and the location on the other. European Standardisation requires a common terminology to facilitate communication and enable a better understanding regarding the design, performance, manufacturing and installation of various types of fences.

Diversity of possible impacts of vehicles on a guardrail protection is extremely diverse in terms of speed, angle, vehicle type and other parameters relating to vehicle and road. Consequently, real shocks observed in the field may differ considerably from standard test conditions. Proper application of the standard must allow, for a new guardrail, the identification of some characteristics susceptible to ensure a maximum security abandoning those unacceptable. However, some difficulties are encountered for the achievement of guardrails extremities providing an adequate safety. Extremities, defined as the start or end section of a barrier must ensure adequate performance at impact. This end is a smooth transition area that goes from one restraint capacity 0 to a maximum restraint of the guardrail, without creating additional risk for frontal impact.

Since the most critical direction of the shock starts from the most slider guardrail to the stiffest one, the direction of the impact must start from the barrier with the lowest level of protection to that with the highest level of protection, provided that dynamic deflection of the latter to be less during the test guardrail.

If the highest dynamic deflection (after impact) of the safety barrier is higher than the guardrail dynamic deflection showing less protection, it must be chosen the impact direction for each test separately and the justification of these choices must be recorded in test report. If the two fences are in the same class of protection, the shock direction must start from the barrier with largest dynamic deflection to that with the smallest one.

The establishment of compulsory standards for the design, construction and modernization of roads and the location of buildings and facilities in their area, must ensure, in terms of high-tech and economic efficiency, the combination of judicious system of public roads and exploitation, establishing a network unit of roads, maintenance and superior capitalization of existing road network, upgrading, saving and rational use of land, increase efficiency and road safety.

\section{ACKNOWLEDGEMENTS}

This paper is the result of a research in the frame of CEEX211 national project. The authors would like to acknowledge to ICECON S.A. for the sponsorship and financial support throughout the project development.

\section{REFERENCES}

[1] Matthews, F.L.; Davies, G. A.O., Hichings, D. \& Soutis, C. (2000). Finite element modelling of composite materials and structures, ISBN 185573422 2, Woodhead Publishing Ltd.

[2] Agarwal, B.D.; Broutman, L.J. \& Chandrashekhara, K. (2006). Analysis and performance of Fiber Reinforced Composites, New York, $3^{\text {rd }}$ Edition

[3] Vinson, J.R.. \& Sierakovski, R.L. (2008). The behaviour of structures composed of composite materials, Second Edition, Kluwer Academic Publishers

[4] Chang, F.K. \& Chang, K.Y. (1987). A progressive damage model for laminated composites containing stress concentrators. Journal of Composite Materials, pp. 834-855, Vol. 21, No.9, September 1987, ISSN 0021-9983

[5] Chen, J.; Crisfield, M.A.; Kinloch, A.J.; Matthews, F.L.; Busso, E. \& Qiu, Y. (1999). Predicting progressive delamination of composite materials specimens via interface elements. Mechanics of Composite Materials and Structures, pp. 301-317, Taylor \& Francis Group, Volume 6, Issue 4

[6] O'Brien, K.T. (1985). Analysis of local delaminations and their influence on composite laminate behaviour. ASTM STP-876, Philadelphia 